\title{
Are happier people less vulnerable to rumination, anxiety, and post-traumatic stress? Evidence from a large scale disaster

\author{
Cristian Zanon ${ }^{1 *}$, Claudio S. Hutz ${ }^{2}$, Caroline T. Reppold ${ }^{3}$ and Markus Zenger ${ }^{4,5}$
}

\begin{abstract}
The present longitudinal study tested hypotheses about the relationship of subjective well-being and neuroticism with rumination, anxiety, and post-traumatic stress in university students after a large scale disaster. Measures of subjective well-being and personality were obtained two months before the 2013 Santa Maria's fire. Measures of rumination, PTSD and anxiety were collected five months after the disaster with the same students. The results provide evidence that life satisfaction correlated negatively with rumination, anxiety, and post-traumatic stress. Positive affect presented similar but slightly smaller negative correlations with these variables, while negative affect presented higher correlations with rumination, anxiety, and post-traumatic stress. These findings provide evidence that subjective well-being components may constitute important predictors of psychopathological symptomatology after a disaster and may be helpful to plan clinical interventions.
\end{abstract}

Keywords: Subjective well-being, Neuroticism, Rumination, Anxiety, Post-traumatic stress

\section{Background}

On January 27, 2013, a fire in a nightclub killed 242 people and injured another 600. Most of the people at the nightclub were undergraduate students from six local universities who were about returning classes. This tragedy occurred in Santa Maria, a major college city with approximately 250,000 citizens in southern Brazil. Soon after the disaster, a national mobilization was organized to provide health care to the victims and their families, and official mourning was declared for 30 days in the city. This disaster is considered the second most devastating fire in the country (BBC 2014; 2015; Wikipédia 2015).

Two months before the fire, data on subjective wellbeing (Zanon et al. 2013; Zanon et al. 2014) and personality (Nunes et al. 2010) were collected in two local universities as part of a project about academic adaptation in university students. Five months after the disaster, a second wave of measures about rumination (Nolen-Hoeksema and Morrow 1991), anxiety (Spitzer et al. 2006)), and post-traumatic stress (Bringhenti et al.

\footnotetext{
* Correspondence: cristianzanon@yahoo.com.br

${ }^{1}$ Department of Psychology, Universidade São Francisco, Itatiba, Brazil Full list of author information is available at the end of the article
}

2010) was collected. This design allows us to evaluate the impact of subjective well-being and personality variables on rumination, anxiety, and post-traumatic stress.

The discovery of vulnerability and protective factors involved in the development of psychopathology after traumatic experiences may contribute to the understanding of response to trauma and to the improvement of interventions. Traditionally, symptoms of deficit-related variables (e.g., depression, anxiety, and stress) have been investigated as predictors of future disorders, and less attention has been given to how protective factors may prevent or attenuate the onset of psychopathological symptoms. This paper adds to the existing literature that happier people may be less vulnerable to the development of rumination, anxiety, and post-traumatic stress in the context of large scale disasters.

\section{Subjective well-being, neuroticism, and psychopathologies}

Life satisfaction, positive affect, and absence of negative affect constitute the components of subjective wellbeing (SWB: Diener 1994), a construct extensively studied by positive psychology and associated with desirable outcomes such as success (Lyubomirsky et al. 2005), longevity, and mental health (Diener and Chan 2011). 
Life satisfaction is the cognitive component of SWB, and characterizes life contentment as a whole, taking into account people' subjective judgments about their lives. Positive and negative affect constitute the frequency and intensity that people experience positive and negative emotions in their lives (e.g., cheerful, enthusiastic, inspired vs. blue, hostile, and nervous respectively).

Souza et al. (2008) demonstrate that negative affect is an important predictor of posttraumatic stress symptoms after stressful situations, and Moberly and Watkins (2008) propose the existence of a reciprocal relation between negative affect and rumination. If these relationships apply to stressful situations in general, we would also expect an association of negative affect with rumination and PSTD after a large scale disaster. This study addresses this hypothesis.

The relationships between affects and personality have been extensively documented (Costa and McCrae 1980; McCrae and Costa 1991). While negative affect is related to neuroticism, positive affect is associated with extraversion (DeNeve and Cooper 1998; Steel et al. 2008). Despite some authors' claim that the associations of negative affect with neuroticism and positive affect with extraversion are so high that they evaluate the same construct under different names (Tellegen and Waller: Exploring personality through test construction: development of the Multi-dimensional Personality Questionnaire (MPQ), unpublished), our study provides evidence that positive affect, negative affect, extraversion, and neuroticism are differently related to rumination, anxiety, and post-traumatic stress.

Neuroticism is a broad personality factor composed of traits related to emotional distress (Claridge and Davis 2001) depression and anxiety (Clark et al. 1994; Hayward et al. 2000; Roelofs et al. 2008), rumination (Roelofs et al. 2008), post-traumatic stress disorder (Breslau and Schultz 2013), and potentially with everything related to emotional distress. Some researchers argue the correlations observed between neuroticism and other deficit-oriented constructs might be inflated due to item overlap (Ormel et al. 2004; Claridge and Davis 2001). This seems the case especially between neuroticism facets (e.g., depression and anxiety) and corresponding psychopathologies with the same name (Uliaszek et al. 2009). To address this issue, we selected scales to assess the outcomes (e.g., rumination, anxiety, post-traumatic stress) with the lower possible item content similarity with neuroticism facets (e.g., vulnerability, emotional instability, lack of energy, and depression).

Compared to the other Big Five factors (e.g., extraversion, agreeableness, conscientiousness, and openness: McCrae and John 1992), neuroticism presents the highest correlations with psychopathological symptoms (Roelofs et al. 2008) and is possibly one of the most important indicators of depression, rumination, anxiety, and post-traumatic stress before large scale disasters. Only a few longitudinal studies are able to investigate the role of specific variables in the onset of psychopathology before disasters (see, for examples, Felton et al. 2013; La Greca et al. 1994; NolenHoeksema and Morrow 1991) or before a trauma had occurred (Breslau and Schultz 2013). To our knowledge, no research has examined the relevance of subjective wellbeing and neuroticism on the development of rumination, anxiety, and post-traumatic stress. This is one of the central aims investigated in the present study.

\section{Rumination and psychopathology}

Rumination comprises a style of thinking characterized by repetitive and negative thoughts about the self (NolenHoeksema 1991) that potentiates and increases the period of depressive symptomatology. Rumination about stressful events intensifies negative affect and impairs recovery (Nolen-Hoeksema and Morrow 1991; Nolen-Hoeksema 2000). When associated with neuroticism, rumination predicts vulnerability to dysphoria (Roberts et al. 1998), anxiety, and depression (Roelofs et al. 2008). Ruminative thinking about disasters is also common in post-traumatic stress disorder (Michael et al. 2007), and evidence suggests rumination mediates the relationship between neuroticism and psychopathology (Roelofs et al. 2008), possibly through the exacerbation of negative mood (Lyubomirsky and Tkach 2004). Despite considerable research linking rumination with psychopathology, not much is known about which factors predict rumination.

Evidence suggest rumination constitutes a response to negative mood (Rippere 1977), and can be perceived by ruminators as a potential way to solve their problems (Wells and Matthews 1994), although it most often exacerbates negative mood, impairs concentration, and problemsolving tasks (Lyubomirsky and Tkach 2004). Another approach supposes that people ruminate to achieve particular goals and reduce perceived discrepancies (Brotman and DeRubeis 2004; Martin and Tesser 1996). Following the second approach, we might think that unhappy people present larger discrepancies between real and ideal life conditions, and, for this reason, are more likely to ruminate. This paper evaluates this possibility.

\section{This study}

Large scale disasters are likely to threaten self-conceptions about security and adequacy of life conditions and may require new information accommodations. Rumination certainly constitutes a way of dealing with such types of situations, and may predispose posttraumatic stress, depression, and anxiety. In this process, some personal characteristics can increase vulnerability to psychopathology, while others can prevent it. This paper investigates if happier people are less vulnerable to symptoms after a stressful event. 
This study provides an opportunity to investigate the possible role of subjective well-being and personality factors on the development of rumination, anxiety, and post-traumatic stress within a naturalistic setting. This design provides more control over the event and the period between the event (fire) and the outcomes (Wave 2 ). These are relevant issues on longitudinal studies because: a) different nature of stressful events might present different impact on the outcomes, and b) time difference between the event and post testing can provide misleading results because time attenuates symptoms (Felton et al. 2013). Because the event was virtually the same to everyone and at the same time, our study does not present such limitations.

This study aims to evaluate: a) the relationship of subjective well-being with rumination, post-traumatic stress, and anxiety, and b) the relationships of the big five factors of personality (and neuroticism facets) with rumination, post-traumatic stress, and anxiety. Five hypotheses guide our study:

Hypothesis 1: Neuroticism and its facets, especially depression, predict rumination, post-traumatic stress and anxiety.

Hypothesis 2: Neuroticism and its facets are more associated with rumination, post-traumatic stress, and anxiety than subjective well-being components. Except for negative affect, we would not expect life satisfaction and positive affect correlate higher with rumination, posttraumatic stress, and anxiety than neuroticism facets. Hypothesis 3: Literature suggests that rumination starts with a perceived discrepancy between ideal and real conditions. We propose that people who perceive that their lives are far from ideal are more likely to ruminate than people who believe their lives are fine. If so, lower life satisfaction might facilitate rumination because life expectations are far from ideal life conditions. Thus, we expect a negative correlation between these variables. Hypothesis 4: Literature suggests rumination exacerbates negative affect, and that negative affect and rumination are reciprocally associated (Nolen-Hoeksema 1991; Moberly and Watkins 2008). Based on the evidence presented, we expect negative affect predicts rumination. Hypothesis 5: Souza et al. (2008) verified negative affect predicts post-traumatic stress symptoms after a stressful event - a peacekeeping mission in Haiti. We aim to replicate this finding with a different stressful event - a large scale fire. Thus, we expect a positive correlation between negative affect, and PTSD.

\section{Method}

\section{Participants and procedures}

Participants were 33 undergraduate students (28 female) with mean age of 22.2 years $(S D=4.5)$ who answered the questionnaires before and after the fire. Wave 1 was composed of students who participated in the project, "Academic Adaptation, Personality, and Subjective WellBeing in University Students," before the fire. This project was approved by Ethics Committee. Seven months later students were emailed and invited to participate of Wave 2. No information about the participants' involvement with the fire was available. This is a convenience sample, and study is on accordance with ethical aspects of research.

\section{Instruments}

The Affect Scale (Zanon et al. 2013) is a self-reporting test that assesses affects as traits, this instrument was built based on PANAS-X (Watson and Clark 1994) and on the Brazilian adapted version of PANAS. The content of the items was defined after a content validity study conducted with college students that described important and frequent emotions in their life. The Affect Scale presented convergent validity with the Brazilian version of PANAS. Strong correlations between positive $(r=.73)$ and negative $(r=.74)$ affect items were found. This test is comprised of 20 items (10 for positive affects and 10 for negative affects) answered on a Likert-type scale from 1 (does not describe me at all) to 5 (describes me very well). The items are sentences, instead of adjectives, that describe past and present emotions. Adequate internal consistency - alpha coefficient - for positive (.83) and negative (.77) items were found.

The Satisfaction with Life Scale (SWLS: Diener et al. 1985) assesses respondents' current satisfaction with their life in general. The SWLS consists of five questions which are rated on Likert-type scales from 1 (strongly disagree) to 7 (strongly agree). The Brazilian version of the SWLS also presents evidences of validity and reliability (Zanon et al. 2013).

The Factorial Personality Battery (FPB: Nunes et al. 2010) is a self-reporting instrument comprised of 126 items modeled on the Five Factor Personality Model. This scale provides an efficient and objective evaluation of extraversion, neuroticism, agreeableness, conscientiousness, and openness to experience. This test was developed for use with Brazilians. It was built based on personality descriptors used by Brazilians (Hutz et al. 1998) and comprises part of the content and structure of other available Brazilian-developed factorial personality scales used to assess neuroticism (Hutz and Nunes 2001), extraversion (Nunes and Hutz 2006), agreeableness (Nunes and Hutz 2007), and openness (Vasconcellos and Hutz 2008).

Items in the PFB were constructed in the form of sentences that describe the participant's attitudes, beliefs, and feelings. They are answered on a Likert-type scale from 1 (does not describe me at all) to 7 (describes me at all). The PFB showed adequate internal consistency, 
alpha coefficient, for each one of the factors: neuroticism .89 , extraversion .84 , agreeableness .85 , conscientiousness .83, and openness .74 .

The Ruminative Response Scale (RRS; Nolen-Hoeksema and Morrow 1991) is a self-report instrument that evaluates rumination through 22 items describing responses to depressed mood. The items are rated on a Likert-type scale ranging from 1 (almost never) to 4 (almost always). A Brazilian version of this scale was adapted to this study by two professors, and one doctorate student with expertise on test adaptation and rumination. One professor and the doctorate student translated and provided two distinct versions of the scale that was evaluated and refined initially by the other professor, and later by the three.

Posttraumatic Stress Disorder Checklist-Civilian Version (PCL-C: Weathers et al. 1993) is a self-report checklist of PTSD symptoms that indicate the degree to which participants have been bothered by that particular symptom over the past month. This checklist is based closely on the DSM-IV criteria, and participants rate each item from 1 (not at all) to 5 (extremely). The Brazilian version of this instrument was adapted by Bringhenti et al. (2010) and indicates validity and reliability evidences. However, the rate scale was changed to 0 to 10 in the Brazilian version. The authors mention that patients presented difficulties to choose a value among 1 and 5 .

Generalized Anxiety Disorder (GAD-7: Spitzer et al. 2006) is a brief measure of anxiety symptoms composed of seven items rated from 0 (not at all) to 5 (nearly every day). The scale presents evidences of validity and reliability. The Brazilian version of this scale was retrieved from the website: http://www.phqscreeners.com/.

\section{Results}

The variables studied were initially analyzed with descriptive statistics. Most of them presented low skewness and kurtosis, indicating variability in the scores. Exceptions were agreeableness, vulnerability, depression, positive affect, and anxiety that presented kurtosis higher than 1. Next, Pearson's correlations between Wave 1 and Wave 2 measures were conducted (Table 1).

The three subjective well-being components were more correlated with rumination indicating closer association among these variables. Negative affect produced significant correlations with the three outcomes, while life satisfaction correlated significantly with anxiety. The four personality factors, openness, agreeableness, conscientiousness, and extraversion, presented non-significant correlations with rumination, PTSD symptoms, and anxiety pointing out low association among them. Neuroticism, and its facet depression, presented significant, and positive correlations with the outcomes indicating depression symptoms are relevant predictors of rumination, PTSD, and anxiety.
Table 1 Correlations between Waive 1 (personality, and subjective well-being) and Waive 2 (rumination, post-traumatic symptoms, and anxiety) measures $(N=33)$

\begin{tabular}{lccc}
\hline Waive 1 & \multicolumn{3}{l}{ Waive 2} \\
\cline { 2 - 4 } & & \multicolumn{3}{l}{ Rumination } & $\begin{array}{c}\text { Posttraumatic } \\
\text { stress symptoms }\end{array}$ & Anxiety \\
\hline Personality & -.05 & .03 & .06 \\
Openness & .07 & .01 & -.13 \\
Agreableness & .12 & -.29 & -.20 \\
Conscientiousness & -.26 & .06 & .11 \\
Extraversion & $.44^{* *}$ & .24 & .20 \\
Neuroticism & $.34^{*}$ & .09 & .08 \\
N1 - Vulnerability & .27 & .21 & .14 \\
N2 - Emotional instability & .24 & .15 & .07 \\
N3 - Passivity/lack of energy & $.61^{* *}$ & $.35^{*}$ & $.40^{*}$ \\
N4 - Depression & & & \\
Subjective well-being & $-.37^{*}$ & -.25 & -.30 \\
Positive affect & $.43^{*}$ & $.39^{*}$ & $.39^{*}$ \\
Negative affect & $-.49^{* *}$ & -.29 & $-.41^{*}$ \\
Life satisfaction & & &
\end{tabular}

Note. ${ }^{*} p<.05 ;{ }^{* *} p<.01$

\section{Discussion}

This paper assessed the possible role of subjective wellbeing and neuroticism on the development of rumination, post-traumatic stress, and anxiety after a large scale disaster - the Santa Maria's fire. Our findings point out that Subjective well-being indicates relevant relations with rumination, post-traumatic stress, and anxiety. Only neuroticism, among the other personality factors, was significantly associated with future psychopathological symptoms, and that depression, one of its facets, was the most important indicator. Together, these results show that not only deficit-oriented variables are important to the onset of symptomatology development, and that resource-oriented variables might have an important role on the prediction of psychopathology associated with traumatic situations.

Our first hypothesis was that neuroticism and its facets would predict rumination, post-traumatic stress, and anxiety, once evidence point out neuroticism is associated with many deficit-oriented variables (Claridge and Davis 2001; Ormel et al. 2004). The small relationships of neuroticism with posttraumatic stress disorder $(r=.24)$ and anxiety $(r=.20)$, however, only partially corroborate this hypothesis. On the other side, the moderate association found with rumination $(r=.44)$ support it. Depression presented the highest association with the outcomes pointing out that depressive characteristics are among the most important indicators of subsequent rumination, PTSD, and anxiety. The other neuroticism facets (e.g., vulnerability, emotional instability, and lack of 
energy) were most related with rumination suggesting that the broad traits of emotional distress that characterize neuroticism play a role on the development of rumination.

Literature indicates neuroticism is associated with anxiety (Roelofs et al. 2008), and the development of post-traumatic stress disorder after exposure to stressful situations (Breslau and Schultz 2013). This study provides small evidences that neuroticism contributes directly to the development of anxiety and post-traumatic stress disorder. However, the higher association verified between neuroticism and rumination suggests that traits of emotional distress predict the development of rumination, a strong predictor of psychopathology (NolenHoeksema 2000) and a mediator between neuroticism and psychopathologies (Roelofs et al. 2008). This study is the first to provide evidence that neuroticism predict rumination after a large scale disaster.

Our second hypothesis was that neuroticism and its facets would be more associated with rumination, anxiety and PTSD than subjective well-being components (except negative affect). We did not corroborate this hypothesis because the correlations of neuroticism, its facets, and subjective well-being components with the outcomes were similar (except that depression that correlated higher with most outcomes). These results indicate SWB components are at least as relevant to the prediction of rumination, anxiety, and PTSD as neuroticism is.

One argument against the relevance of SWB to this issue may be that negative affect, one component of SWB, maybe also considered a component of neuroticism (Costa and McCrae 1992) associated with anxiety (Schwartz and Koenig 1996) and PTSD (Souza et al. 2008). From this perspective, if negative affect items had contributed to the final neuroticism score, the associations would have been higher. We, in fact, verified high associations of negative affect with neuroticism $(r=.59)$, vulnerability $(r=.47)$, emotional instability $(r=.77)$, and depression $(r=.39)$, supporting as expected that negative affect is closely related with neuroticism. However, life satisfaction presented similar correlations with rumination, anxiety, and PTSD, and despite smaller, positive affect correlations with these variables should not be neglected. Thus, our results suggest that happier people ruminate less and may be more resistant to anxiety, and PTSD.

Our third hypothesis, that life satisfaction is negatively associated with rumination, received support in our study. More satisfied people presented lower rumination five months after a large scale disaster. This finding seems to corroborate Martin and Tesser (1996) alternative view about rumination development that suggests the discrepancy between real and ideal conditions motivate rumination. The corroboration of our fourth hypothesis indicates people who live frequent negative affect are more likely to ruminate after a stressful event. Additionally, positive affect and rumination are negatively correlated. Together, these results indicate that happier people are less vulnerable to rumination after a stressful event. Considering that rumination and negative affect creates a loop of negative and repetitive thoughts that exacerbates negative consequences (e.g., negative affect, depressive symptoms, stress (Lyubomirsky and Tkach 2004), happier people may have less reason and inclination to ruminate. Happy people are more likely to feel: a) a sense of adequacy about their lives, b) frequent emotions like confidence, enthusiasm, joyful, and c) less negative emotions as irritation, dissatisfaction, and loneliness. Such characteristics may prevent the initial development of rumination and reduce the periods of rumination about stressful events.

The fifth hypothesis aims to replicate Souza et al. (2008) results about the relationships between negative affect and PTSD in a different stressful event - a fire. Souza et al. suggest that negative affect seems to worsen the consequences of being exposed to a traumatic situation. Our findings support this previous result. Negative affect, in fact, predicts PTSD, and might constitute a vulnerability factor to the development of PTSD to people who experience the stress of a disaster.

\section{Clinical implications}

Large scale disasters may affect thousands of people in places without appropriate number of qualified professionals and health care services to attend survivors, families that lost someone, and others somehow involved. The literature suggests that after stressful events people with previous history of depression should have priority on the treatment because they are more likely to develop depression (Felton et al. 2013).

We encourage clinicians to recognize the importance of disasters, but not to stimulate victims and their families to ruminate about this. The impact of news on television about disasters might increase rumination tremendously (Felton et al. 2013), and it might have an even greater impact on unhappy people. Thus, we suggest professionals advise victims and their families to avoiding watching television programs focused on the incident or even to avoid television entirely. Additionally, positive activities (Layous et al. 2014; Lyubomirsky and Layous 2013), therapeutic techniques to improve mood like behavioral activation (Dobson et al. 2008), and treatments focused on the modification of cognitive bias (Hakamata et al. 2010), and metacognitive believes (Wells and King 2006), may constitute prolific interventions to community members affected by disasters.

Some limitations of this investigation concerns the sample studied. This investigation is based on a reduced sample size which restricts its external validity. However, 
this weakness may be compensated by its ecological validity. Almost all participants were women, so the study may fail to reflect relevant differences in the manifestation of symptoms in men. Because women tend to present higher levels of depression and negative affect than men (Nolen-Hoeksema and Jackson 2001), the correlations might be overestimated due to the lack an adequate proportion of men in the sample. The high refusal rate (96.4\%) suggests that only more cooperative students accepted to participate of the Wave 2 follow up. In other words, the sample appears to be homogeneous in terms of participants' collaborative characteristics. We did not ask students important information about how many friends, brothers, or sisters they lost in the fire, or if they were in the nightclub during the tragedy. These data may explain part of the variance in psychopathological symptoms not accounted for by the personality factors and SBW components. Lastly, this is a correlational study, which does not allow us to infer causality relations between the variables of wave 1 on the outcomes. Because we do not know if unhappier people were also more ruminative or with higher levels of anxiety before the fire, we recommend caution on the interpretation of these results.

We do not believe, though, the sample homogeneity and smallness restrict considerably the relevance of the presented findings. Although they are not fully representative of the victim population, our study participants did provide meaningful evidence concerning the power of subjective well-being and neuroticism in the prediction of rumination, post-traumatic stress, and anxiety after a large scale disaster. Moreover, they might contribute to the development of interventions for victims in similar situations.

\section{Conclusion}

This study highlights the possible protective role of prior subjective well-being components to the development of rumination, PTSD, and anxiety after a stressful event - a fire. Life satisfaction, negative affect, positive affect, and neuroticism - especially depression - constitute important predictors of rumination, PTSD, and anxiety. The associations of subjective well-being components with the outcomes suggest they might be useful indicators of mental health after stressful events.

\section{Competing interest}

The authors declare that they have no competing interests.

\section{Authors' contributions}

CZ was responsible for planning, data collection, statistical analysis, discussion and drafting of the article. CSH was responsible for planning, discussion and drafting of the article. CTR was responsible for planning, discussion and drafting of the article. MZ was responsible for planning, discussion and drafting of the article. All authors read and approved the final manuscript.

\section{Author details}

'Department of Psychology, Universidade São Francisco, Itatiba, Brazil. ${ }^{2}$ Department of Psychology, Universidade Federal do Rio Grande do Sul, Porto Alegre, Brazil. ${ }^{3}$ PPG Ciências da Saúde e PPG Ciências de Reabilitação, Universidade Federal de Ciências da Saúde de Porto Alegre, Porto Alegre, Brazil. ${ }^{4}$ Faculty of Applied Human Studies, University of Applied Sciences Magdeburg and Stendal, Stendal, Germany. ${ }^{5}$ Department of Medical Psychology and Medical Sociology, University of Leipzig, Leipzig, Germany.

Received: 8 March 2016 Accepted: 7 April 2016

Published online: 19 April 2016

\section{References}

BBC. Santa Maria: dor e tristeza às vésperas de aniversário de tragédia. 2014. Retrived from: http://www.bbc.com/portuguese/noticias/2014/01/140127_ santa_maria_justica_jdc_an. Accessed May 2013.

BBC. Dois anos depois, incêndio da Kiss ainda 'parece ontem'. 2015. Retrived from, http://www.bbc.com/portuguese/noticias/2015/01/150127_santamaria_ doisanos_jc. Accessed May 2013.

Breslau N, Schultz L. Neuroticism and post-traumatic stress disorder: a prospective investigation. Psychol Med. 2013;43(8):1697-702. doi:10.1017/S0033291712002632.

Bringhenti ME, Luft CDB, Oliveira WF. Transtorno do estresse póstraumático em acidentes de trânsito: Validação de escala. Psico-USF. 2010;15(2):193-203.

Brotman MA, DeRubeis RJ. A comparison and appraisal of theories of rumination. In: Papageorgiou C, Wells A, editors. Depressive rumination: Nature, theory, and treatment. Chichester: Wiley; 2004. p. 177-84.

Claridge G, Davis C. What's the use of neuroticism? Personal Individ Differ. 2001;31:383-400.

Clark LA, Watson D, Mineka S. Temperament, personality, and the mood and anxiety disorders. J Abnorm Psychol. 1994;103(1):103-16. doi.org/10.1037/0021-843X.103.1.103.

Costa PT, McCrae RR. Influence of extraversion and neuroticism on subjective well-being: happy and unhappy people. J Pers Soc Psychol. 1980;38(4):668-78. doi:10.1037/0022-3514.38.4.668.

Costa Jr PT, McCrae RR. Revised NEO Personality. Inventory (NEO-PI-R) and NEO Five-Factor Inventory (NEO-FFI) professional manual. Odessa: Psychological Assessment Resources; 1992.

DeNeve KM, Cooper H. The happy personality: a meta-analysis of 137 personality traits and subjective well-being. Psychol Bull. 1998;124(2):197-229. doi:10.1037/0033-2909.124.2.197.

Diener E. Assessing subjective well-being: Progress and opportunities. Soc Indic Res. 1994;31(2):103-57. doi:10.1007/BF01207052.

Diener E, Chan MY. Happy people live longer: Subjective well-being contributes to health and longevity. Appl Psychol Health Well-Being. 2011;3(1):1-43. doi.org/10.1111/j.1758-0854.2010.01045.x.

Diener E, Emmons R, Larsen R, Griffin S. The satisfaction with life scale. J Pers Assess. 1985;49:91-5. doi.org/10.1207/s15327752jpa4901_13.

Dobson KS, Hollon SD, Dimidjian S, Schmaling KB, Kohlenberg RJ, Gallop RJ. Randomized trial of behavioral activation, cognitive therapy, and antidepressant medication in the prevention of relapse and recurrence in major depression. J Consult Clin Psychol. 2008;76(3):468-77. doi.org/10.1037/0022-006X.76.3.468

Felton JW, Cole DA, Martin NC. Effects of rumination on child and adolescent depressive reactions to a natural disaster: The 2010 Nashville Flood. J Abnorm Psychol. 2013;122(1):64-73. doi.org/10.1037/a0029303.

Hakamata Y, Lissek S, Bar-Haim Y, Britton JC, Fox NA, Leibenluft E. Attention bias modification treatment: A meta-analysis toward the establishment of novel treatment for anxiety. Biol Psychiatry. 2010;11(1):982-90.

Hayward C, Killen JD, Kraemer HC, Taylor CB. Predictors of panic attacks in adolescents. J Am Acad Child Adolesc Psychiatry. 2000;39(2):207-14. doi.org/10.1097/00004583-200002000-00021.

Hutz CS, Nunes CHSS. Escala Fatorial de Ajustamento Emocional/Neuroticismo (Factorial Scale of Emotional Adjustmen/Neuroticism). São Paulo: Casa do Psicólogo; 2001.

Hutz CS, Nunes CHSS, Silveira AD, Serra J, Anton M, Wieczoreck LS. The development of the big five markers for personality assessment in Brazil. Psicologia: Reflexão e Crítica. 1998;11(2):395-411.

La Greca AM, Silverman WK, Wasserstein SB. Factors affecting children's reactions to a natural disaster. Child Youth Family Services Quarterly. 1994;17:2-5. 
Layous K, Chancellor J, Lyubomirsky S. Positive activities as protective factors against mental health conditions. J Abnorm Psychol. 2014;123:3-12.

Lyubomirsky S, Layous K. How do simple positive activities increase well-being? Curr Dir Psychol Sci. 2013;22:57-62.

Lyubomirsky S, Tkach C. The consequences of dysphoric rumination. In: Papageorgiou C, Wells A, editors. Rumination: Nature, theory, and treatment. Chichester: John Wiley \& Sons; 2004. p. 21-41.

Lyubomirsky S, King L, Diener E. The benefits of frequent positive affect: does happiness lead to success? Psychol Bull. 2005;131(6):803-55. doi:10.1037/0033-2909.131.6.803.

Martin LL, Tesser A. Some ruminative thoughts. In: Wyer Jr RS, editor. Ruminative Thoughts. Mahwah: Lawrence Erlbaum; 1996. p. 1-47.

McCrae RR, Costa PT Jr. Adding Liebe and Arbeit:The full five-factor model and wellbeing. Pers Soc Psychol Bull. 1991;17(2):227-32. doi:10.1177/014616729101700217.

McCrae RR, John OP. An introduction to the five-factor model and its applications. J Pers. 1992;60(2):175-215. doi.org/10.1111/j.1467-6494.1992.tb00970.x.

Michael T, Halligan SL, Clark DM, Ehlers A. Rumination in posttraumatic stress disorder. Depress Anxiety. 2007;24:307-17. doi.org/10.1002/da.20228.

Moberly NJ, Watkins ER. Ruminative self-focus and negative affect: an experience sampling study. J Abnorm Psychol. 2008;117(2):314-23. doi.org/10.1037/0021-843X.117.2.314.

Nolen-Hoeksema S. Responses to depression and their effects on the duration of depressive episodes. J Abnorm Psychol. 1991;100:569-82. doi:10.1037/0021-843X.100.4.569.

Nolen-Hoeksema $\mathrm{S}$. The role of rumination in depressive disorders and mixed anxiety/depressive symptoms. J Abnorm Psychol. 2000;109:504-11. doi.org/10.1037//0021-843X.109.3.504.

Nolen-Hoeksema S, Jackson S. Mediators of the gender difference in rumination. Psychol Women Q. 2001;25:37-47. doi.org/10.1111/1471-6402.00005.

Nolen-Hoeksema S, Morrow J. A prospective study of depression and posttraumatic stress symptoms after a natural disaster: The 1989 Loma Prieta earthquake. J Pers Soc Psychol. 1991;61:115-21. doi:10.1037/0022-3514.61.1.115.

Nunes CHSS, Hutz CS. Development and validation of an extraversion scale in the Big Five Personality model. Psico-USF. 2006;11(2):147-55.

Nunes CHSS, Hutz CS. Development and validation of an Agreeableness scale in the Big Five personality model. Psicologia: Reflexão e Crítica. 2007;20(1):20-5.

Nunes CHSS, Hutz CS, Nunes MFO. Factorial personality battery. São Paulo: Casa do Psicólogo; 2010.

Ormel J, Rosmalen J, Farmer A. Neuroticism: A non-informative marker of vulnerability to psychopathology. Soc Psychiatry Psychiatr Epidemiol. 2004;39(11):906-12. doi.org/10.1007/s00127-004-0873-y.

Rippere V. "What's the thing to do when you're feeling depressed?": a pilot study. Behav Res Ther. 1977;15:185-91.

Roberts JE, Gilboa E, Gotlib $\mid H$. Ruminative response style and vulnerability to episodes of dysphoria: gender, neuroticism, and episode duration. Cogn Ther Res. 1998;22(4):401-23.

Roelofs J, Huibers M, Peeters F, Arntz A. Effects of neuroticism on depression and anxiety: rumination as a possible mediator. Personal Individ Differ. 2008;44(3):576-86. doi.org/10.1016/j.paid.2007.09.019.

Schwartz JAJ, Koenig LJ. Response styles and negative affect among adolescents. Cogn Ther Res. 1996;20:13-36. doi.org/10.1007/BF02229241.

Souza WF, Figueira I, Mendlowicz MV, Volchan E, Mendonca-de-Souza AC, Duarte AF, Monteiro da Silva AM, Marques-Portella C, Mari JJ, Coutinho ES. Negative affect predicts posttraumatic stress symptoms in Brazilian volunteer United Nations peacekeepers in Haiti. J Nerv Ment Dis. 2008;196(11):852-5. doi.org/10.1097/NMD.0b013e31818b4682.

Spitzer RL, Kroenke K, Williams JB, Lowe B. A brief measure for assessing generalized anxiety disorder: The GAD-7. Arch Intern Med. 2006;166(10):1092-7. doi.org/10.1001/archinte.166.10.1092.

Steel P, Schmidt J, Schultz J. Refining the relationship between personality and subjective well-being. Psychol Bull. 2008;134(1):138-61. doi:10.1037/0033-2909.134.1.138.

Uliaszek AA, Hauner KKY, Zinbarg RE, Craske MG, Mineka S, Griffith J, Epstein A. An examination of content overlap and disorder-specific predictions in the associations of neuroticism with anxiety and depression. J Res Personal. 2009:43:785-94. doi.org/10.1016/j.jrp.2009.05.009.

Vasconcellos SJL, Hutz CS. Development and validation of an openness scale. AvaliaçãoPsicológica. 2008;7(2):135-41

Watson D, Clark LA. The PANAS-X: Manual for the positive and negative affect schedule - expanded form. 1994. Retrieved from: http://ir.uiowa.edu/cgi/ viewcontent.cgi?article=1011\&context=psychology_pubs. Accessed May 2013.
Weathers FW, Litz BT, Herman DS, Huska JA, Keane TM. The PTSD Checklist (PCL): Reliability, validity, and diagnostic utility. In: Paper presented at the 9th Annual Conference of the ISTSS, San Antonio, TX. 1993.

Wells A, King P. Metacognitive therapy for generalized anxiety disorder: an open trial. J Behav Ther Exp Psychiatry. 2006;37(3):206-12. doi.org/10.1016/j.jbtep.2005.07.002.

Wells A, Matthews G. Attention and emotion: a clinical perspective. Hove: Lawrence Erlbaum; 1994.

Wikipédia. Incêndio na boate Kiss. 2015. Retrived from: https://pt.wikipedia.org/ wiki/Inc\%C3\%AAndio_na_boate_Kiss. Accessed May 2013

Zanon C, Bastianello MR, Pacico JC, Hutz CS. Desenvolvimento e validação de uma escala de afetos positivos e negativos. Psico-USF. 2013;18(2):193-201.

Zanon C, Bardagi MP, Layous K, Hutz CS. Validation of the satisfaction with life scale to Brazilians: evidence of measurement noninvariance between Brazil and the US. Soc Indic Res. 2014;119:443-53. doi:10.1007/s11205-013-0478-5.

\section{Submit your manuscript to a SpringerOpen ${ }^{\circ}$ journal and benefit from:}

- Convenient online submission

- Rigorous peer review

- Immediate publication on acceptance

- Open access: articles freely available online

- High visibility within the field

- Retaining the copyright to your article

Submit your next manuscript at $>$ springeropen.com 